\title{
Essential dataset for ambulatory ear, nose, and throat care in general practice: an aid for quality assessment
}

\author{
Tom af Klercker, Erik Trell, Per-Gotthard Lundquist
}

\begin{abstract}
Objective-To describe the documentation of care for the usual range of ear, nose, and throat (ENT) problems seen in primary care as a basis for developing a computerised information system to aid quality assessment.
\end{abstract}

Design-Descriptive study of the pattern of ENT problems and diagnoses and treatment as recorded in individual case notes. Setting-The primary health care centre in Mjölby, Sweden.

Patients-Consultations for ENT problems from a $10 \%$ sample randomly selected from all consultations $(n=22600)$ in one year. From this sample 375 consultations for ENT problems (16\% of all consultations) by 272 patients were identified. Main measures-The detailed documentation of each consultation was retrieved from the individual records and compared with the data required for a computer based information system designed to help in quality management.

Results-Although the overall picture gained from the data retrieved from the notes suggested that ENT care was probably adequate, the recorded details were limited. The written case notes were insufficient when compared with the details required for a computerised system based on an essential dataset designed to allow assessment of diagnostic accuracy and appropriateness of treatment of ENT problems in primary care.

Conclusion-There is a gap between the amount and the type of information needed for accurate and useful quality assessment and that which is normally included in case notes. More detailed information is needed if general practitioners' notes are to be used for regular quality assessment of ENT problems but that would mean more time spent on keeping notes This would be difficult to justify.

Implications-The routine information systems used at this primary healthcare centre did not produce sufficient documentation for quality assessment of ENT care. This dilemma might be resolved by specially designed desktop computer software accessed through an essential dataset.

(Quality in Health Care 1997;6:35-39)

Keywords: care provision; ear nose and throat; general practice; quality improvement.
One of the aims of current developments in health care in many countries including Sweden, is to increase the role of primary care.$^{1-3}$ More people are likely to be cared for entirely in the primary care setting. To ensure that (with the increased emphasis on primary care) the delivery of ambulatory care is of good quality, co-ordination between the primary healthcare centres and hospital specialist services is essential..$^{1-3}$ Our group and others ${ }^{4-14}$ have shown that the integration and communication between the two sectors will be enhanced with the development of appropriate information support systems. ${ }^{41516}$ These systems require, for each distinct area of care or specialty, a common register of basic terms (thesaurus) ideally mediated by interactive clear text desktop computer software. ${ }^{68-1016}$

Ear, nose, and throat (ENT) problems account for a large proportion of consultations in primary health care in Sweden. ${ }^{1718}$ An important initiative by the Swedish Association of General Practice and ear, nose, and throat specialists has led to the development of a written agreement (called "PRIMEAR" PRIMary care EAR, nose, and throat agreement) that outlines the respective roles of general practitioners and ENT specialists in the care of patients with ENT problems (table 1). ${ }^{19}$ This agreement covers a wide range of ENT conditions and includes statements about differential diagnosis and indications for referral to specialist care. The care of most people with ENT problems presenting to primary healthcare teams in Sweden is conducted along these guidelines ${ }^{20}$ - even though this agreement itself has not yet been ratified by many ENT clinics. Many consultations for ENT symptoms with Swedish general practitioners are for minor, usually self limiting problems. ${ }^{1718}$ The PRIMEAR agreement recognises this and the diagnosis of common cold is not included in the PRIMEAR agreement as it is too unspecific.

The aim of the agreement is to ensure that patients with ENT problems are seen rapidly and thoroughly assessed for the appropriate level of care - which for most cases is a local primary care centre. Thus the basis for developing information systems that could link primary and secondary care and could provide easy access to the sort of information necessary for quality assessment is already established.

Transference from paper record to desk top computer systems may be more than a matter of a change in technology. We were keen to find 
Table 1 Example from the PRIMEAR agreement. (PRIMary care EAR, nose, and throat)

\begin{tabular}{|c|c|c|}
\hline Diagnosis & Primary care & Specialist clinic or admission \\
\hline ENT diagnosis (general) & $\begin{array}{l}\text { Most patients with acute ENT diseases can be } \\
\text { diagnosed, treated, and controlled within the primary } \\
\text { healthcare service. } \\
\text { Expected fraction } 70 \%-90 \%\end{array}$ & $\begin{array}{l}\text { Acute respiratory obstruction, acute dysphagia, foreign bodies in } \\
\text { throat or oesophagus, exacerbations, complications, etc, education } \\
\text { cases. } \\
\text { Expected fraction } 10 \%-30 \%\end{array}$ \\
\hline Otitis media & All cases except & $\begin{array}{l}\text { Complications, treatment failure, }>4 \text { earlier occasions, age }<2 \mathrm{y} \text {, } \\
\text { hearing impairment, chronic disease }\end{array}$ \\
\hline Eustachian catarrh & All cases except & $\begin{array}{l}\text { Complications, treatment failure, }>4 \text { earlier occasions, age }<2 \text { y, } \\
\text { hearing impairment, chronic disease, duration }>8 \text { weeks }\end{array}$ \\
\hline Wax in the ear & All cases except & Removal failure, complications membrane rupture, status unclear \\
\hline Hearing impairment & Primary investigations & Further investigation, treatment hearing aids \\
\hline Vertigo & Primary classification & $\begin{array}{l}\text { In most cases admission to ENT or neurological or other } \\
\text { specialist }\end{array}$ \\
\hline Epistaxis & Primary treatment in all cases & $\begin{array}{l}\text { Tampon failure, complications, control of posterior tamponade, } \\
\text { tumour, or other organic background }\end{array}$ \\
\hline Sinusitis & Primarily all cases except & $\begin{array}{l}\text { Frontal sinusitis, children with ethmoidal sinusitis, treatment } \\
\text { failure, complications }\end{array}$ \\
\hline Allergic rhinoconjunctivitis & All cases except & $\begin{array}{l}\text { Unclear diagnosis or status, treatment failure, need for specialist } \\
\text { allergy investigations }\end{array}$ \\
\hline Laryngotracheobronchitis & Mild cases & Respiratory stridor, treatment failure \\
\hline
\end{tabular}

\begin{tabular}{|lc|}
\hline Sociodemographic data: & Medical history of symptons: \\
Age & For how long \\
Sex & Initial symptom \\
Other Data: & Seriousness \\
Body temperature & What kind: \\
Concurrent disease & If pain: \\
Concurrent medication & Type \\
Hearing impairment & Intensity \\
Discharge: & Where \\
If yes: & If vertigo: \\
From where & Severity \\
& Type \\
\hline
\end{tabular}

Preliminary essential data for ambulatory primary health care of ENT patients diagnosed as having: allergic rhinitis, epistaxis, eustachian catarrh, laryngotracheobronchitis, neck swellings, hearing impairment, external otitis, otitis media, pharyngitis, sinusitis, tinnitus, tonsillitis, vasomotor rhinitis, vertigo, wax in the ear.

out what sort of information is normally recorded in primary care case notes when people present with ENT problems. This paper reports the result of a study that assessed the quality of recorded data in case files of patients with ENT problems presenting to one primary healthcare centre and looked at these as a resource for quality improvement. The working hypothesis of the investigation was that the information recorded in patients' notes is unlikely to provide sufficient documentation for this purpose.

Both the hypothesis and the approach have practical implications. The World Health Organisation has stated that today's information systems do not provide the kinds of information necessary to achieve the targets or to measure progress towards achieving them, ${ }^{26}$ and that one of the most important performance measures of health care is compliance with practice guidelines. An approved method complying with such guidelines is often measuring rates of clinical performance to provide information for quality improvement. $^{27}$

To construct an essential dataset containing information about the diagnosis of ambulatory care of the ENT problems likely to be seen in general practice ${ }^{25}$ that could be used to support quality assessment, we used a model ${ }^{6}$ based on a variety of sources including the standard authoritative textbooks (box). ${ }^{21224}$ We then tested this essential dataset on the range of ENT problems seen in routine practice in a primary healthcare centre and thus were able to examine the practicalities of using performance measures for quality assessment and improvement.

\section{Materials and methods}

In this study we focused on the 30 most frequent ENT diagnoses described in the PRIMEAR agreement. All case notes in the primary healthcare centre of Mjölby (catchment population about 23000 ) were searched. A $10 \%$ sample representative of age and sex was selected by including any visit to the centre between 1 July 1988 to 30 June 1989 by anyone born on the $2 \mathrm{nd}, 12 \mathrm{th}$, and $22 \mathrm{nd}$ of each month. We investigated all consultations from this sample that had been for any ENT problem outlined in the PRIMEAR agreement. These were identified from the diagnostic data base kept by the primary healthcare centre in Mjölby. Details of the top 10 diagnoses and other comparative data were also taken in a standard way from the same source for the quality assessment. ${ }^{27-32}$

Each individual case file was read and the following details were collected by one of us ( $T$ af $\mathrm{K})$ : (a) the diagnosis in terms described in the essential dataset; ${ }^{25}(b)$ all criteria relevant to the ENT problems.

As well as collecting all information relevant to the diagnosis that had been recorded, we also noted the absence of information that would have been required by the information system to make the diagnosis. All of the case notes in the study sample were examined once more so that at least one year had passed between the studied visits and the follow up to find any late mishap after the diagnoses studied.

The data were transferred to a computer program for statistics (StatView 4.0 Abacus Concepts 1992) and compared with the data ${ }^{2731-34}$ required for the computerised essential data system for ENT care (table 2). ${ }^{21-24}$ To test whether the data were representative and compensated for selection bias of the ENT 
diagnosis sample, they were compared with the total number of visits to the same primary healthcare centre the next year (table 3 ).

\section{Results}

The study sample consisted of 343 visits by 272 patients. One hundred and nine patients $(40 \%)$ were men. Ages ranged from one to 86 , with a median of 18 reflecting the high frequency of ENT problems occurring in childhood. In the study period, the total number of diagnoses made in the primary healthcare centre was 25345 (22 614 visits in 19876 different patients) and for the sample 2566 (2290 visits in 2084 patients).

The number of individual ENT diagnoses, as defined by the Swedish primary care ENT agreement, in the 272 patients was 375 . The 10 most frequent ENT diagnoses constituted $94 \%$, and the five most frequent ENT diagnoses almost $85 \%$ of all ENT diagnoses (table 3). The most frequent diagnosis was otitis media which made up one third of the total. The top five ENT diagnoses accounted for about $16 \%$ of all diagnoses for all patients attending the Mjölby primary healthcare centre in the study period.

Only 12 of the 343 consultations for ENT problems resulted in a referral for specialist opinion. All these were within the guidelines of the PRIMEAR agreement.

For many of the cases much of the information that would be required as essential data for computer was not included in the case notes (table 2). Some of the prescribed practice guidelines ${ }^{21-2427}$ were recorded frequently and others rarely.

The number of discrete pieces of essential information for the computer to support the diagnosis of any condition varies. The greatest being 16 for vertigo (table 2). But the mean number of pieces of information actually recorded in the notes was usually less than that required for the essential dataset. For example in otitis media the mean number recorded in the medical notes was seven compared with 15 required for the computer; for tonsillitis four out of 10; sinusitis eight of 13; external otitis seven of 11 ; wax in the ear four of 13 ; eustachian catarrh five of 10; acute pharyngitis four of five; laryngotracheobronchitis six of six; allergic rhinitis five of 14 ; vasomotor rhinitis seven of 14 ; vertigo six of 11 ; and epistaxis eight of eight. Table 2 shows examples of the variation in recording data in case notes.

Table 3 Examples of ENT diagnoses from control and sample data

\begin{tabular}{|c|c|c|c|c|c|}
\hline \multirow[b]{2}{*}{ Diagnosis } & \multicolumn{3}{|l|}{ Control } & \multicolumn{2}{|l|}{ Sample } \\
\hline & Number & $\%$ Of ENT & $\%$ Of total & Number & $\%$ Of ENT \\
\hline Otitis media & 1725 & 21.7 & 5.7 & 126 & 33.6 \\
\hline Sinusitis & 784 & 9.9 & 2.6 & 66 & 17.6 \\
\hline Wax in the ear & 335 & 4.2 & 1.1 & 25 & 6.7 \\
\hline Vertigo & 257 & 3.2 & 0.9 & 16 & 4.3 \\
\hline Eustachian catarrh & 191 & 2.4 & 0.6 & 8 & 2.1 \\
\hline Epistaxis & 77 & 1.0 & 0.3 & 7 & 1.9 \\
\hline Laryngotracheobronchitis & 19 & 0.2 & 0.1 & 1 & 0.3 \\
\hline Other specified ENT diagnoses & 256 & 3.2 & 0.1 & 10 & 2.9 \\
\hline Top 10 ENT diagnoses & 5698 & 94.5 & 19.0 & 361 & 96.3 \\
\hline Total diagnoses per period & 30040 & - & - & 25345 & - \\
\hline Total ENT diagnoses & 6030 & 100 & 20.1 & 375 & 100 \\
\hline
\end{tabular}

\section{Discussion}

Systems that strengthen documentation and provide a basis for evaluation and feedback about decision making are important for quality improvement. ${ }^{27}$ But this survey has shown that the documentation of clinical details about patients presenting to a primary care centre for ENT problems are limited, and therefore unlikely to be of much use for detailed quality assessment. In all, only $46 \%$ of the clinical details necessary for setting up a computerised information system based on an essential dataset were in fact recorded in the written case notes.

The case mix and the proportion of work that involved ENT problems at the Mjölby primary healthcare centre are representative of the situation in Sweden and are close to the PRIMEAR estimations. There was nothing in our follow up to suggest that the clinical performance of the practitioners of the Mjölby primary healthcare centre was anything other than satisfactory. The number of patients seen and the types of diagnoses made were similar to those expected from the PRIMEAR estimations. Moreover, during the study period no complaints were filed and no unexpected events were recorded in the study sample. Thus physicians seemed to make the appropriate diagnoses, draw the right conclusions, and refer the right cases to the hospital. But as the details recorded in the notes were limited this remains a subjective assessment.

Some further broad judgements about the process of consultation can be inferred from the patterns of the clinical details that were recorded. Most doctors when dealing with common and straightforward problems - for instance, with cases of acute tonsillitis involve themselves only in the practical aspects of care, once it is clear that the patient has pain in the throat. A similar pattern was found with the management of patients with otitis media. However, in the management of vertigo - a condition that may have several causes and may not be as straightforward in either diagnosis or management and requires more thorough examination of the clinical details the symptoms and signs were recorded more thoroughly and were more in keeping with the range of details deemed to be required for the computerised information system. Thus it seems that the easier a diagnosis is to make and perhaps the more commonly it is seen, the fewer the details that appear in the records. And for cases of wax in the outer ear or epistaxis few clinical details apart from the diagnosis were recorded, as would be expected from the standards set by the computerised essential dataset.

Including all diagnostic details in the case notes is considered to be an important quality measure. ${ }^{27334}$ In the case notes of ENT problems at Mjölby documented conformity with practice guidelines ${ }^{27}$ would have been considered poor. However, actual practice is likely to have been good. There are several reasons why it may be unsatisfactory and potentially risky to have insufficient documentation. Earlier studies show that an insufficient 
documentation severely hampers medical audit and quality assessment. ${ }^{27} 33$ Poor documentation does not necessarily mean bad care, but good documentation shows clearly both what and how care was delivered. Failure to keep detailed records may thus place an unjustified doubt on the care providers and will also made it difficult for them to show their full capacities.

So, why is documentation so limited? Lack of time and lack of relevance to the eventual outcome may both contribute. It may be argued that time spent on documenting details of the care of straightforward problems such as sore throats is not a good use of valuable time. However, the introduction of computer systems as well as demanding more information may also provide support that allows quick and complete documentation. At peak hours, under stress, or in emergency situations, it may be difficult to complete written records of all data, particularly if those data do not have an immediate purpose but are to be used for a quality assessment at a later date. A primary care centre with heavy, fluctuating, and multifarious work load could be well served by information support systems that could for example stream line administrative tasks. Delays in typing dictated notes may also contribute to the limited documentation.

There are many ways in which electronically stored clinical data could contribute to the management of the process of clinical care. But moving from paper to electronic records is as much a matter of cultural as technological change. If essential datasets are to become part of support systems then those constructing them will need to take into account not only current practice and established guidelines but also the need for concise speedily entered notes, preferably mediated by on line computer software. ${ }^{25}$ This should both register and report the diagnostic and therapeutic procedures as a "blue print" as they are performed and, not overburden busy clinicians by demanding a lot of apparently redundant details. The essential dataset should be adjusted to the local case files as they contain all the local knowledge and traditions. Properly designed, such a system could be a sound foundation for good quality assessment. As an extra benefit it could help primary health care to move towards the World Health Organisation goals and document the struggle to reach them.

1 World Health Organisation. Targets for health for all. Targets in support of the European regional strategy for health for all. Copenhagen: WHO, Regional Office for Europe, 1985.

2 Whitehead M. The concepts and principles of equity and health. Copenhagen: World Health Organisation, Regional Office for Europe, 1990.

3 World Health Organisation. Alma ata, primary health care health for all series, No 1. Geneva: World Health Organisation, 1978.

4 Moidu K. Computer-based support for maternal and child care at primary care centres [academic dissertation] . Linköping Faculty of Health Sciences, 1992.
5 Moidu K, Wigertz O, Trell E. A multicenter study of data collection and communication at primary health care centres. $\mathcal{F}$ Med Syst 1991;15:205-20.

6 Moidu K, Singh AK, Bostrom K, Chowdhury S, Trell E, Wigertz O, Kjessler B. Towards an essential dataset: applicability in the domain of maternal health services. Methods Inf Med 1992;31:182-92.

7 Moidu K, Wigertz O, Trell E. Multi-centre systems analysis study of primary health care: a study of socioorganisational and human factors. Int $\mathcal{f}$ Biomed Comput 1992;39:27-42.

8 Singh AK, Moidu K, Trell E, Wigertz O. Impact on the management and delivery of primary health care by a computer-based information system. Comput Methods Programs Biomed 1992;37:55-64.

9 Moidu K, Singh AK, Bostrom K, Wigertz O, Trell E, Kjessler B. MCHS: an application software for family welfare programmes. Med Inf 1992;17:279-91.

10 Moidu K, Singh AK, Wigertz O, Trell E. Computers in primary health care: a cost-effectiveness analysis. In: Lun 92. Amsterdam: Elsevier, 1992:472-7.

11 World Health Organisation. Targets for health for all. The health policy for Europe. Summary of the updated editor September 1991. Copenhagen: WHO, Regional Office for Europe, 1991.

12 Lambert PM, Roger FH. Hospital statistics in Europe. Amsterdam: North-Holland, 1982.

13 Hutchinson A. Designing European minimum datasets for ambulatory care. Med Inf 1991;1:25-7.

14 Moidu K. Application of an essential dataset based computer system in support of maternal and child care. Int $f$ ter system in support of maternal
Biomed Comput 1992;31:159-75.

15 Moidu K, Wigertz O. Computer-based information systems in primary health care: why? $\mathcal{F}$ Med Syst 1989;13:59-65.

16 Flygt C, Homelius B, Jacobsson B, Foldevi M, Trell E. Essential dataset for computer management of distributed primary care services. Medical Information. 1995;20:33141 .

17 Halvarsson L, Hegardt G, Engstrand I. Where does the ear nose and throat patient find his health care? Allmanmedicin 1983;4:244-6. (In Swedish.)

18 Lind M. Outpatient care at ear, nose, and throat clinics can be improved by increased collaboration with primary care. fournal of the Swedish Medical Association 1983;80:4120-2. (In Swedish.)

19 Swedish Medical Association. Agreement between the Swedish Associations of: General Medicine, District Doctors, and Oto-rhino-laryngology on guidelines for management and collaboration regarding patients with ENT-diseases (The PRIMEAR-agreement). Stockholm: Swedish Medical Association, 1984. (Stencil U 80/84; in Swedish).

20 Swedish Board of Health and Welfare 1984:542. Target descriptions for the specialist qualifications of physicians. descriptions for the specialist qualifications of physicians. (In Swedish.)

$21 \mathrm{~S}$ Engquist. ENT-manual. Uppsala: Almqvist o Wiksell, 1989. (In Swedish.)

$22 \mathrm{H}$ Rundcrantz. Ear, nose, and throat diseases. Lund: Studentlitteratur, 1991. (In Swedish.)

23 Hallén O, Anniko M. Ear, nose, and throat diseases. Uppsala: Almqvist and Wiksell, 1991. (In Swedish.)

24 Colman BH. Diseases of the nose, throat and ear, and head and neck, 14th ed. Oxford: Churchill Livingstone, 1992

25 af Klercker T, Trell E, Lundqvist PG. Towards an essential dataset for ambulatory oto-rhino-laryngological care in general practice. Med Inf 1994;19:253-67.

26 World Health Organisation. Priority research for health for all. Copenhagen: WHO, Regional Office for Europe, 1988.

27 Palmer RH. Measuring clinical performance to provide information for quality improvement. Quality Management in Health Care 1996;4:1-6.

28 Jordin B, Rydin L, Trell E. Medical quality indicators. Proposal of a taxonomy. Fournal of the Swedish Medical Associposal of a taxonomy. Fournal of the $S$
ation 1993;90:4124-8. (In Swedish.)

29 Donobedian A. Evaluating the quality of medical care. Milbank Memorial Fund Quarterly 1966;44:166-203.

30 Medical quality board formed [editorial]. Fournal of the Swedish Medical Association 1992;89:921. (In Swedish.)

31 World Health Organisation, Regional Office for Europe. Quality assurance in health care. Report on a WHO working
group, Kiel, 21-25 November 1988. Copenhagen: WHO, group, Kiel,

32 Working Party on Quality Assurance. 13th WONCA Conference on Family Medicine. Vancouver: WONCA, 1992.

33 Mååg L, Swartling PG, Smedby B. Lifelong unnecessary treatment is risked when investigations of B-12 deficiency are not improved. fournal of the Swedish Medical Associationoc 1992;89:984-6. (In Swedish.)

34 Gabbay J, Layton AJ. Evaluation of audit of medical inpatient records in a district general hospital. Quality in Health Care 1992;1:43-7. 